\title{
Growth in haemophilic boys after HIV infection
}

\author{
K J Pasi, M A Collins, A K Ewer, F G H Hill
}

\begin{abstract}
Although failure to thrive has been documented as a major problem in babies with congenital HIV infection, there is little information on whether HIV affects growth in older children who become infected with HIV. The growth of 27 haemophilic boys, in whom HIV seroconversion was recorded between 1981 and 1986, has been assessed to see if the pattern changed after seroconversion. Height and weight recordings were analysed over a mean period of $\mathbf{9 . 2}$ years with a mean duration from HIV seroconversion of 4.5 years (range 2 to 6 years). Height standard deviation scores and ratio of weight to 50th centile for chronological age were calculated. No significant change in growth pattern as judged by height and weight has been observed within this group of boys after HIV seroconversion. Growth assessment continues to be evaluated to see if further progression of HIV disease changes growth pattern in these boys.
\end{abstract}

In congenital HIV infection failure to thrive has been documented as a major problem and an early feature of the disease. In older children, however, many aspects of the natural history of HIV infection remain unclear, particularly with regard to growth and development.

We have studied growth in a cohort of boys with haemophilia A, who have acquired HIV infection through transfusion of factor VIII concentrate, to see if acquisition of HIV infection has altered patterns of growth and development.

\section{Subjects and methods}

A total of 27 boys with haemophilia A attending the Birmingham Children's Hospital have been studied. Twenty six of these boys were severely affected and had a concentration of VIII:C less than $0.01 \mathrm{U} / \mathrm{ml}$ and one had mild haemophilia with a concentration of VIII:C of $0.05 \mathrm{U} / \mathrm{ml}$. HIV seroconversion was recorded in these boys during the period 1981-6.

As part of their routine follow up since diagnosis each boy is seen in clinic regularly and has had his height (Harpenden stadiometer) and weight measured regularly. This has usually been done at least three times each calendar year.

One boy was investigated before HIV seroconversion for constitutional short stature.

At present 10 boys have AIDS related complex and only one boy has progressed to develop clinical AIDS (one episode of pneumonia caused by Pneumocystis carinii). Height standard deviation (SD) scores and ratio of weight to 50th centile for chronological age were calculated using the tables of Tanner et al for British children. ${ }^{1}$

Mean growth, both height and weight, before and after HIV seroconversion were analysed by the Wilcoxon matched pairs signed rank test and year on year changes in height SD score after HIV seroconversion analysed by paired $t$ tests.

\section{Results}

Duration of follow up, age, and duration of HIV seropositivity are summarised in the table. The recent seroconversions (two years ago) occurred in boys who had received a dry heated commercial factor VIII concentrate manufactured from plasma that had not been screened for HIV antibody. ${ }^{2}$ Because of these seroconversions this product was withdrawn from the United Kingdom and subsequently from North America and Europe.

In the cohort there was no significant change in growth in height nor weight after HIV seroconversion (figs 1-3). Similarly there was no significant change in year on year change in height SD score after HIV seroconversion, either between consecutive years or at seroconversion and the last year studied.

The one boy who developed AIDS also continued to grow normally along his respective centile (fig 4). Similarly the one boy with constitutional short stature has continued to grow along an acceptable curve parallel, though below, the 3rd centile since seroconversion (fig 5).

Only one boy has failed to continue to grow along his original centile, showing a period of failing growth from the $75-90$ th to $25-50$ th centile for height (fig 6). This growth reduction began three years before HIV seroconversion and is probably unrelated to it (fig 7).

\section{Discussion}

The normal progression of growth depends on a fine balance of many interrelated factors. Chro-

Data of cohort studied

\begin{tabular}{lcl}
\hline & Mean (SD) & Range \\
\hline Duration of follow up (years) & $9 \cdot 2(2 \cdot 4)$ & $4-14$ \\
Age at time of study (years) & $12 \cdot 8(3 \cdot 6)$ & $6-17$ \\
Duration of HIV seroconversion (years) & $4 \cdot 5(1 \cdot 2)$ & $2-6$ \\
\hline
\end{tabular}

The Children's Hospital,

Ladywood,

Birmingham B16 8ET.

Accepted 26 July 1989 


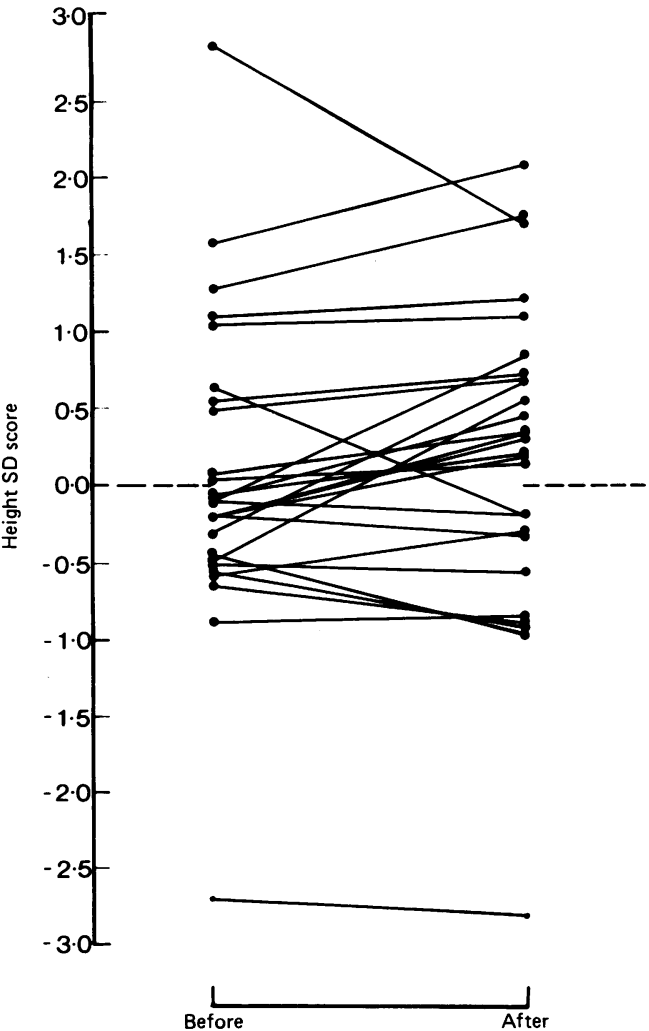

Figure 1 Individual height $S D$ score before and after HIV seroconversion. Note: one boy shows a large fall in height $S D$ score. Despite this fall growth has continued above the 97 th centile.

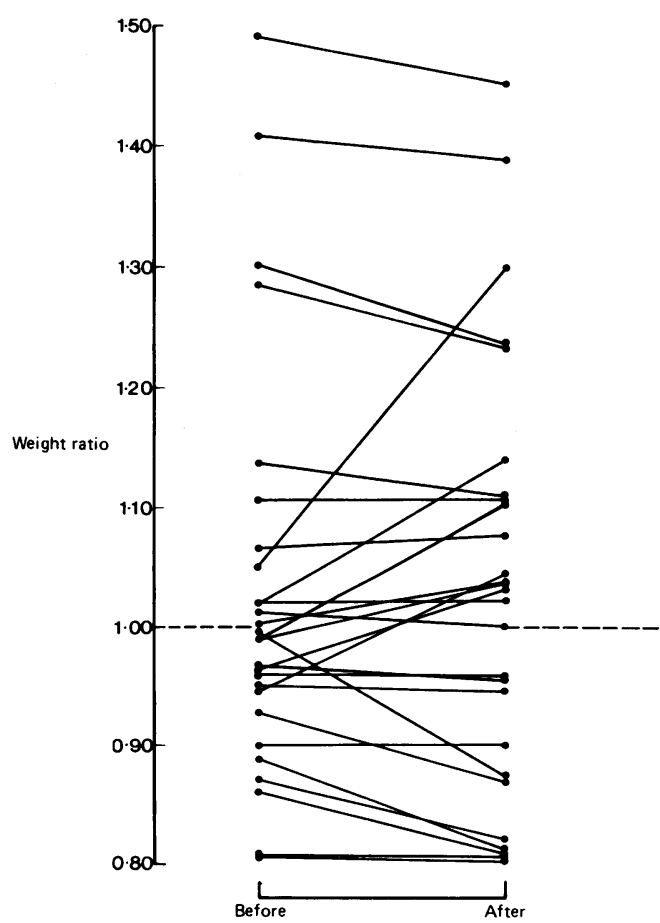

Figure 2 Individual ratio of weight to 50th centile for age before and after HIV seroconversion.
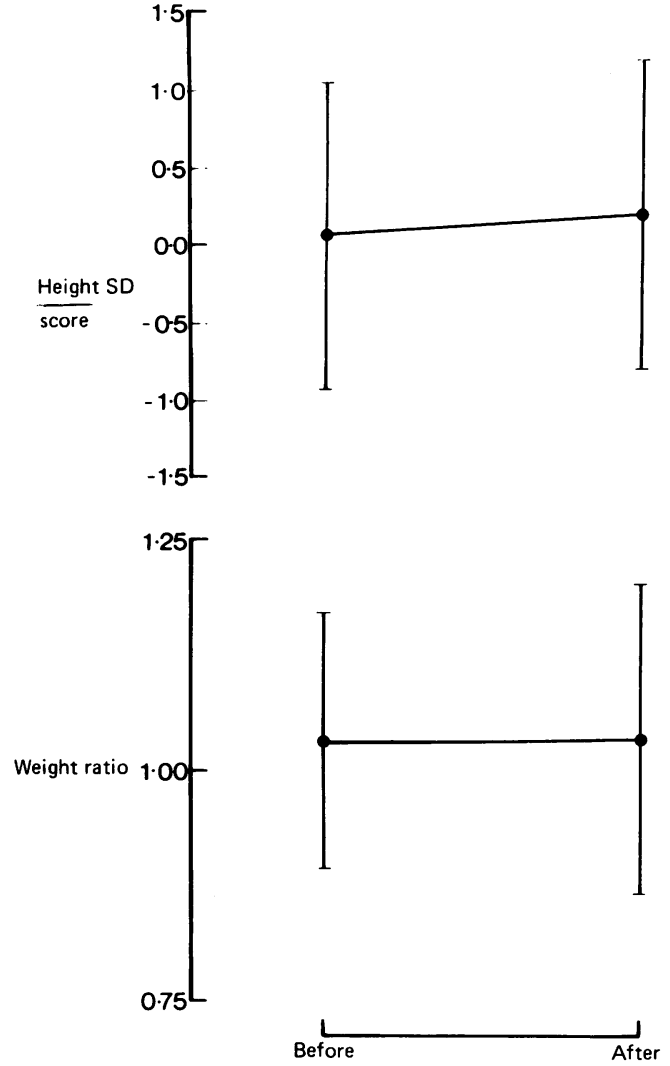

Figure 3 Mean (SD) height SD score and ratio of weight to 50 th centile for age before and after HIV seroconversion.

nic illness is well recognised to affect directly and adversely linear growth in situations such as renal failure, ${ }^{3}$ liver disease, ${ }^{4}$ congenital heart disease, ${ }^{4}$ poorly controlled diabetes mellitus, ${ }^{5}$ and active asthma. ${ }^{6}$

HIV infection can result in a wide range of clinical manifestations, ranging from asymptomatic infection through to profound immunodeficiency characterised by malignancy and opportunistic infection. Growth failure has been described in children with chronic symptomatic HIV infection, AIDS related complex, before the onset of clinical definable AIDS. ${ }^{7}$ Little is known, however, about the effect of asymptomatic chronic HIV infection with regard to growth and development. It has, however, been suggested that growth failure is a feature of chronic HIV infection in haemophilia, though as yet there are no published data to support this.

In the later stages of HIV related disease wasting occurs. No boys in this group studied have yet shown such wasting, presumably as the boys remain relatively well at present, up to six years after seroconversion. This may reflect the relatively better outlook for those who become infected with HIV under the age of 20 years. ${ }^{8}$

The 27 children in this study represent a broad cross section of boys with both symptomatic and asymptomatic HIV infection with infection having been documented for up to six years. In no boy has there been significant growth failure, either of linear growth or body weight, that may be directly attributable to HIV 

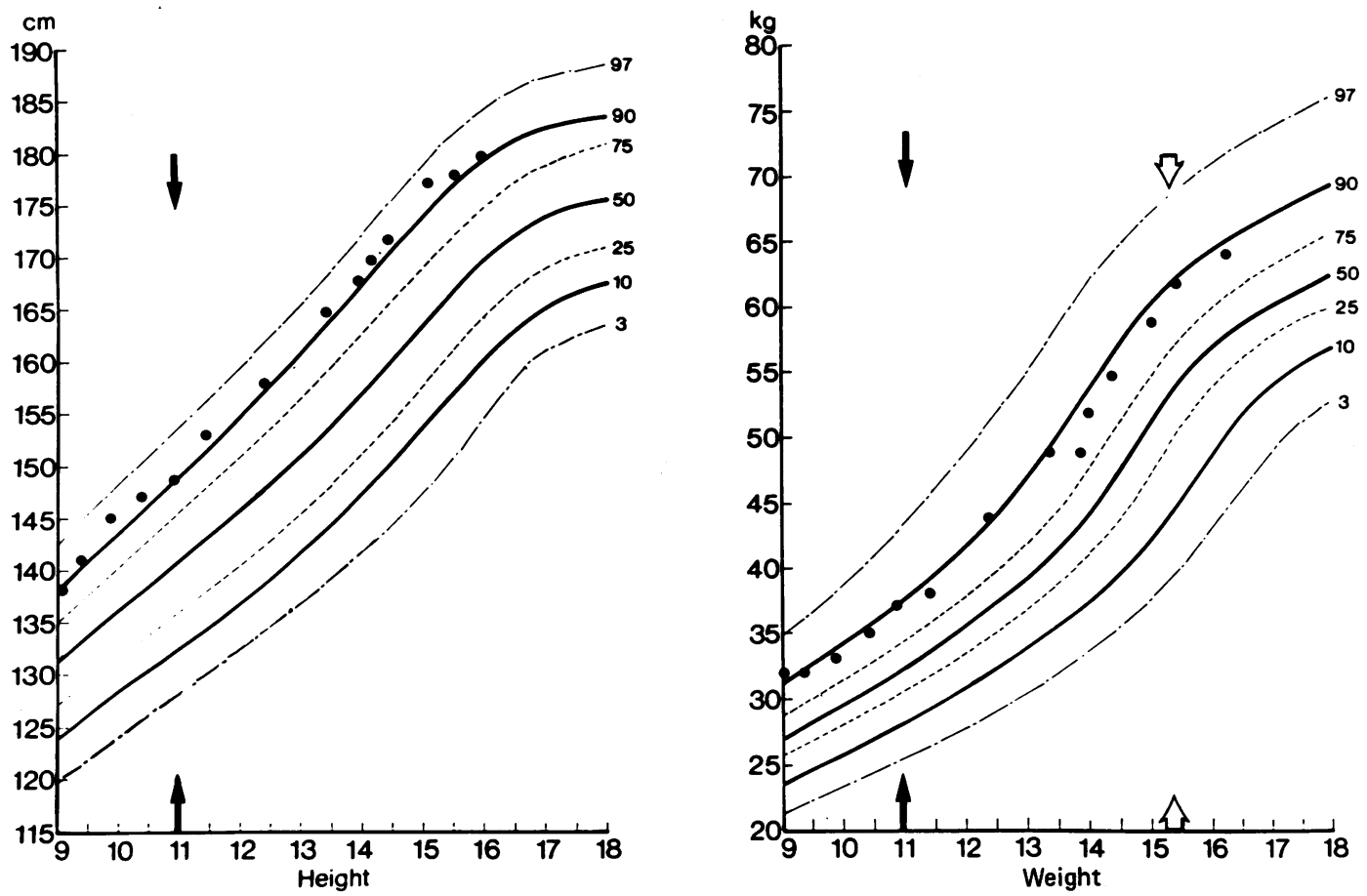

Figure 4 Growth chart, from 9-18 years, of the one boy so far to develop AIDS. Solid arrow represents point of HIV seroconversion. Open arrow represents onset of clinical AIDS. Note: continued progression along the 90th centile.
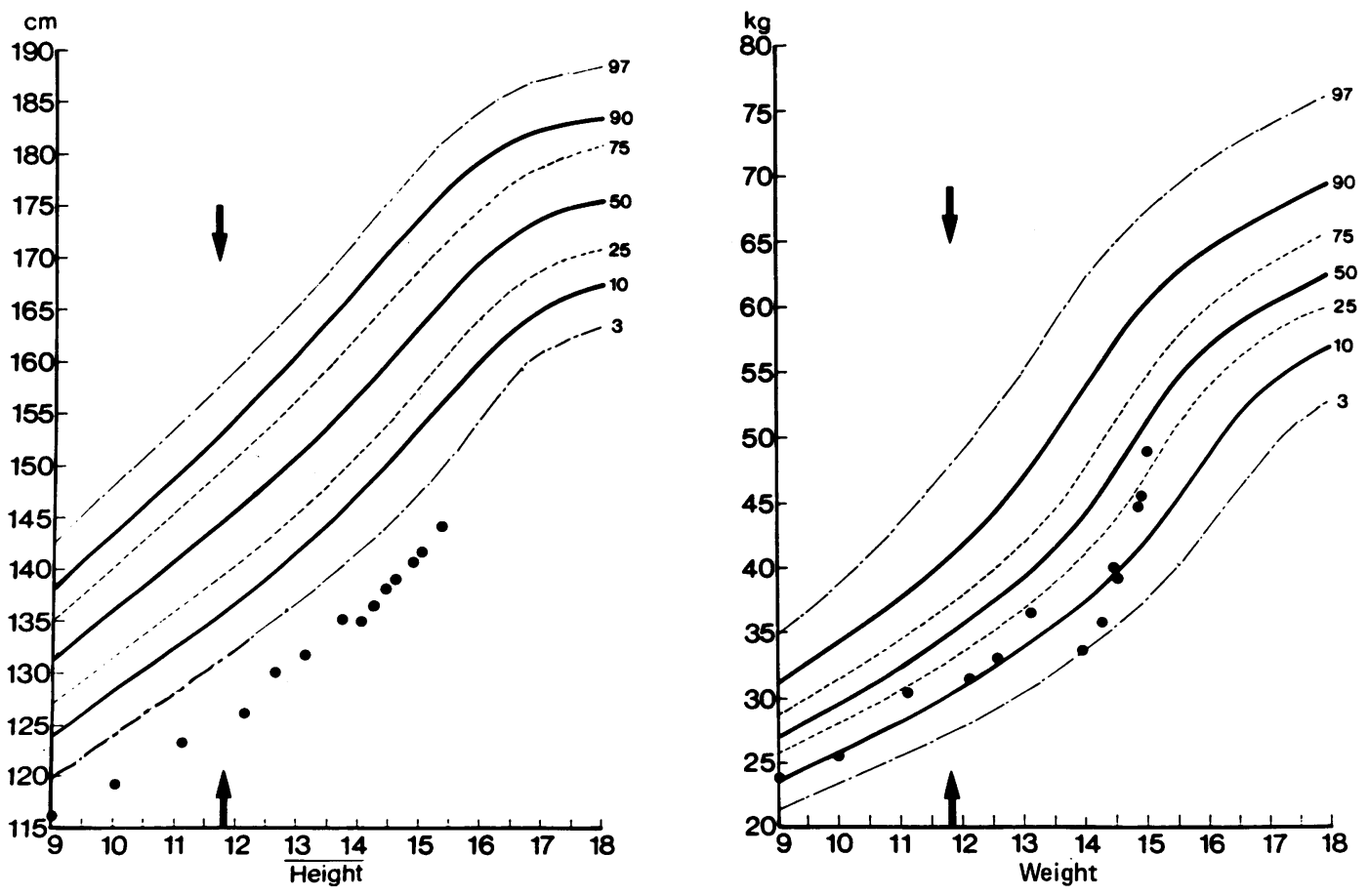

Figure 5 Growth chart, from 9-18 years, of the one boy with constitutional short stature. Arrow represents point of HIV seroconversion. Note: continued acceptable growth along a curve parallel to 3rd centile despite HIV seroconversion. 

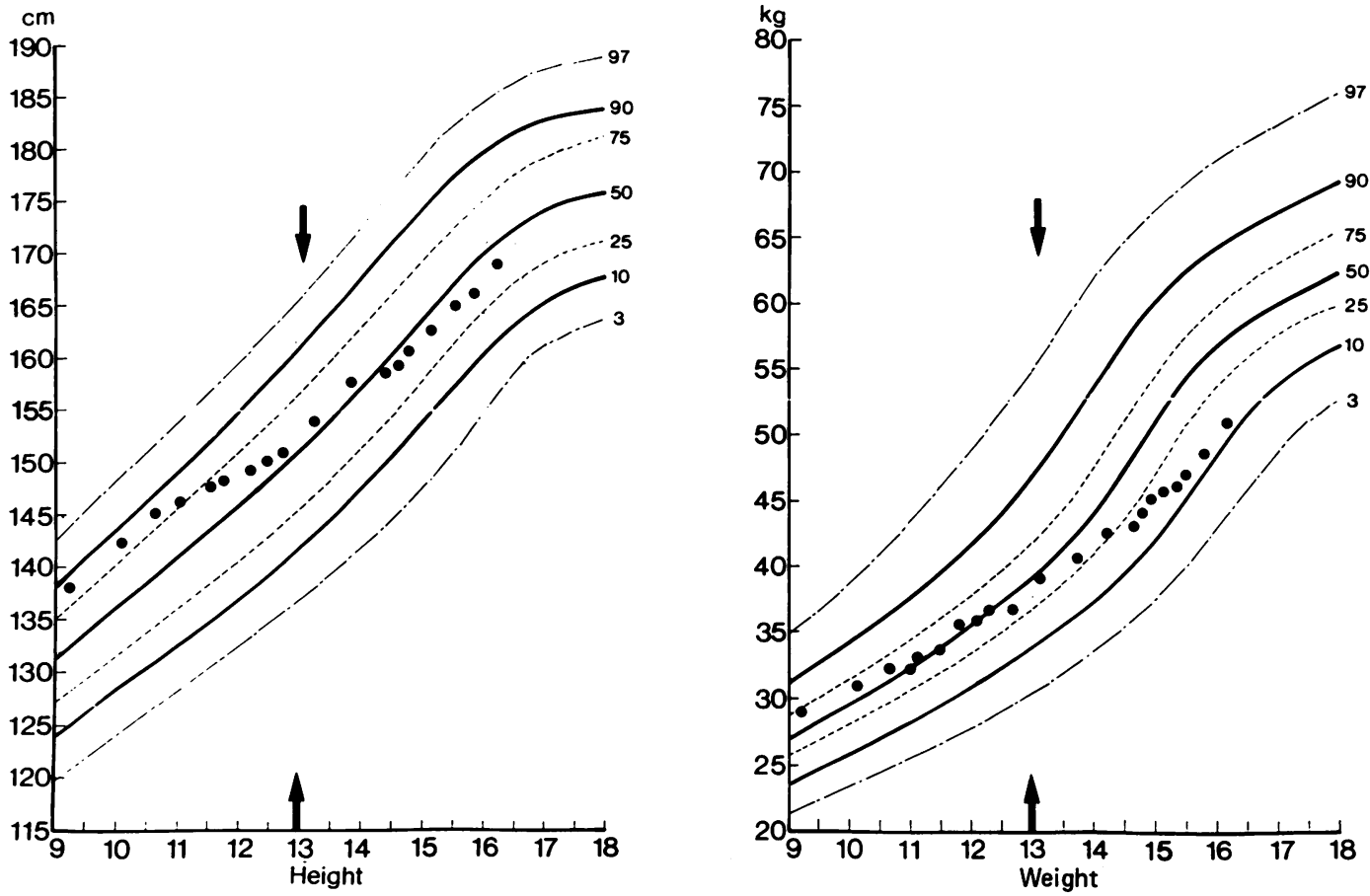

Figure 6 Growth chart, from 9-18 years, of the only boy to show falling growth. Arrow represents point of HIV seroconversion.

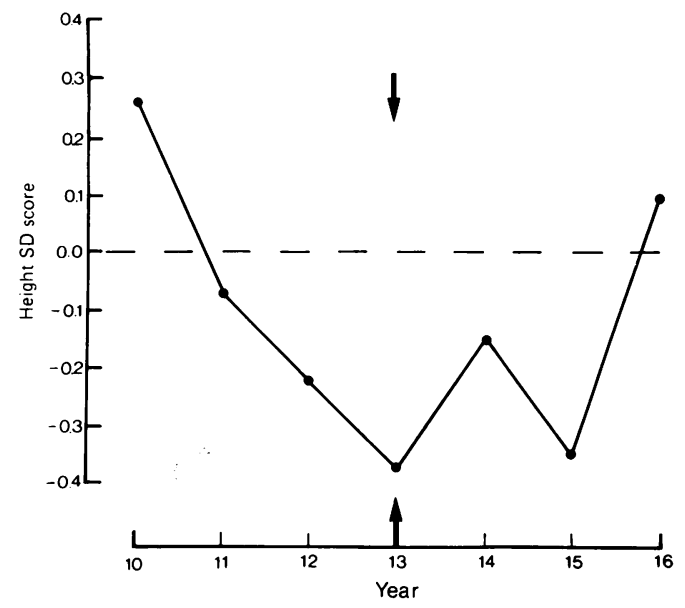

Figure 7 Year on year changes in height $S D$ score for the boy shown in figure 4. Arrow represents time of HIV seroconversion. Note: falling height $S D$ score three years before time of HIV seroconversion.

infection. These boys appear to have continued to grow normally, progressing as expected along their respective centiles for both height and weight. The one boy whose growth did fall off during the study appears to have started to cross the centiles before HIV seroconversion. Without the growth data before HIV seroconversion it would have been easy to have falsely assumed that his fall off in growth was secondary to asymptomatic HIV infection.
HIV infection in haemophilic boys appears to have a modified natural history, perhaps due to the additional immune complications induced by replacement treatment per se. It may be that the apparent preservation of linear growth, up to six years, after seroconversion represents another facet of its differing natural history.

Height and weight continue to be measured regularly in these boys to evaluate whether with time from seroconversion further progression of HIV disease any alteration in growth occurs.

1 Tanner JM, Whitehouse RH, Takaishi M. Standards from birth to maturity for height, weight height velocity and weight velocity: British children, 1965. Part II. Arch Dis Child 1966;41:613-35.

2 Williams MD, Skidmore S, Hill FGH. HIV seroconversion in haemophilic boys receiving heat treated factor VII concentrate. Vox Sang (in press).

3 van Diemen-Steenvoorde R, Donckerwolcke RA, Brackel H Wolff ED, de Jong MCJW. Growth and sexual maturation in children after kidney transplantation. $\mathcal{f}$ Pediat 1987;110:351-6.

4 Kappy MS. Regulation of growth in children with chronic illness. Am F Dis Child 1987;141:489-93.

5 Salardi S, Tonioli S, Tassaoni P, Tellarini M, Mazzanti L, Cacciari $\mathrm{E}$. Growth and growth factors in diabetes mellitus. Arch Dis Child 1987;62:57-62.

6 Shohat M, Shohat T, Kedem R, Mimouni M, Danon YL. Childhood asthma and growth outcome. Arch Dis Child 1987;62:63-5.

7 Kamani N, Lightman H, Leiderman I, Krilov LR. Paediatric acquired immunodeficiency syndrome-related complex: clinical and immunologic features. Pediatr Infect Dis nical and imm

8 Darby SC, Rizza CR, Doll R, Spooner RJD, Stratton IM Thakar B. Incidence of AIDS and excess of mortality Thakar B. Incidence of AIDS and excess of mortality
associated with HIV in haemophiliacs in the United Kingdom: report on behalf of the directors of haemophilia centres in the United Kingdom. Br Med $\mathcal{F} 1989 ; 298$. $1064-8$. 